\title{
Children and survival sex: A social work agenda
}

\section{Natalie Thorburn and Irene de Haan}

Natalie Thorburn is a social worker working in the sexual violence sector and is currently studying towards her Masters in social work, focusing on child involvement in transactional sexual activity. Dr Irene de Haan is a lecturer with the School of Counselling, Human Services and Social Work at the University of Auckland. Her research interests include prevention of child maltreatment and family violence and she chairs regional Family Violence Death Review Panels.

\section{Abstract}

The purchasing of sexual services by adults from children and adolescents affects an unknown proportion of New Zealand youth, and is present in both rural and urban settings. International research shows that on average girls begin using sex for survival between the ages of 12 and 15. It can be argued that the terms used to denote adolescent transactional sex indicate the researchers' moral position of the subject; the terms 'prostitution' and 'client' suggesting equal bargaining power and the terms 'criminality' and 'delinquency' implying victim responsibility. Recent articles are consistent in their comparison of transactional sex to child sexual abuse. Patriarchal ideals relating to gender roles and female sexuality may perpetuate the selling of sexual services by young people. Three primary pathways into survival sex have been identified: through intermediaries, through child sexual abuse and through inadequate protective systems. Children and young people engaged in transactional sex experience a range of adverse effects related to physical, sexual and mental health, and relationships. In New Zealand the use of children under 18 for sexual services is explicitly prohibited, but there are no comprehensive, nation-wide services for victims of transactional sex. Recommendations from the literature support a multi-systemic approach, with an extension of street outreach services, welfare provision and targeted prevention strategies.

\section{Introduction}

Adolescents' use of sex for survival, also called transactional sex or child and teen prostitution, is a damaging manifestation of abuse in society. Goddard (2005) suggests that the use of the word prostitution is intrinsically harmful when it is applied to young people, as it assumes complicity on their part. He refers to the misuse of this phrase as 'lexical redescription' and explains it as abusive in its denial of the criminal nature of sex purchasing from minors (Goddard, 2005). He further proposes that choices of words are linked to thoughts, and as prostitution is synonymous to harlotry, the term fails to reflect the victimisation experienced by children using sex for survival. While commonly perceived to be a transaction or agreement into which both parties freely enter, adolescent involvement in sex for survival is ultimately the sexual abuse of children and demonstrates the inability of society to protect them. The term 'survival sex' more accurately reflects the inherent lack of choice in children's use of sexual transactions to meet their physiological and social needs. Although the prevalence of young people using sex for survival is difficult to measure, it 
has been found that girls using transactional sex usually begin between ages 12 and 15; before they could conceivably be legally, developmentally or socially capable of giving informed consent. Society plays a central role in the ability of perpetrators to purchase sex from children through its failure to challenge and change harmful gendered beliefs and gender inequality. Childhood sexual abuse, homelessness and separation from family of origin often play a part. The consequences of adolescents' engagement in transactional sex are far-reaching, and include negative physical, sexual and mental health outcomes. The purpose of this literature review is to explore perspectives, causes and correlates of the social problem of survival sex and to identify ways in which potential solutions may be consistent with a child protection agenda.

\section{Methods}

Using a multi-database search, the terms teen* OR adolescen* OR child* AND prostitution OR transactional sex OR sex for survival OR sexual exploitation were used to identify relevant literature. This was supplemented with a search for grey literature on New Zealand government and individual organisation websites, and a search of recent news articles. Literature from non-Western countries with significantly different cultural dynamics from New Zealand was excluded. The search yielded 20 relevant resources, which were then synthesised and the results organised thematically.

\section{Results and discussion}

\section{Definition and prevalence}

Sex for survival, sexual exploitation and transactional sex are the preferred terms throughout this literature review. Sex for survival is also referred to as the commercial sexual exploitation of children, child prostitution and opportunistic prostitution, depending on how the authors conceptualise young people's involvement in prostitution (Ministry of Justice, 2001). The descriptions of what can be considered sex for survival vary within the literature but it has been variously described as the utilisation of children and youth to provide for the sexual needs of adults (Herman, 1987); the exchange of sexual services in return for remuneration, (Ministry of Justice, 2002); or the transaction of sex for goods (Svensson, Fredlund, Soransuedin, Priebe \& Wadsby, 2012). The prevalence of young people using transactional sex is difficult to ascertain due to its secretive and hidden nature (Ayre \& Barrett, 2000); however, it is recognised as being present New Zealand in both rural and urban settings (Ministry of Justice, 2002). Internationally, research has found the age by which young people begin trading sex for survival is between 12 and 15 (Jordan, Patel, \& Rapp, 2013; Holger-Ambrose, Langmade, Edinburgh, \& Saewye, 2013; Lukman, et al., 2011; Chase \& Statham, 2005). The victimisation of young people using survival sex is comparable to other types of sexual victimisation; accordingly, it should be regarded as principally a child protection issue (Peace, 2009).

\section{New Zealand}

\section{The policy context and media coverage}

While prostitution in New Zealand has been decriminalised as a result of the Prostitution Reform Act 2003, sections 20, 21 and 22 expressly prohibit the use of any person under 18 for commercial sexual purposes (New Zealand Parliament, 2004). Section 149A of the Crimes 
Act 1961 also disallows the purchasing of sexual services from a person under 18, with the previous gender bias inherent in the legislation being rectified by the Crimes Amendment Act 2001 (Ministry of Justice, 2002). New Zealand has also signed and ratified Convention 182 of the International Labour Conference, which concerns the use of children for commercial purposes, including prostitution (Ministry of Justice, 2002). Following this, government agencies expressed commitment to inter-agency work to address the widespread problem of transactional sex among youth; however, debate continues regarding which department should take responsibility for action (New Zealand Parliament, 2004). Youth involvement in survival sex also remains the topic of media attention, with recent Herald articles with headlines such as 'MP finds 13 year old prostitutes taking $\$ 600$ a night' and 'Girls pimped out by relatives - pastor' featuring calls from conservative politicians and churches to tighten up on prostitution laws and target offenders (Gillies, 2013; Dorday, 2013). Other news articles discuss attempts of police to curb the issue and draw attention to growing numbers of underage girls as young as 13 using transactional sex in parts of Auckland (Shepherd, 2010; Crampton, 2013).

\section{New Zealand research}

Since 2000, only three separate research projects exploring young people's involvement in survival sex in New Zeaand have been identified. The prevalence of sex for survival in a domestic context is impossible to estimate due to its hidden nature, but research by ECPAT NZ (Ending Child Prostitution, Pornography and Trafficking) surveying professionals such as social and youth workers generated a list of 195 (145 of whom are under 16) known young people using transactional sex (Saphira, 2001). A 2004 study of 47 sex workers revealed that the mean age at which participants first used sex for survival was 13.5, with ages ranging from nine-17 (Saphira \& Herbert, 2004c). Similar findings resulted from Plumridge and Abel's (2002) study, in which $31 \%$ of the 303 sex workers reported beginning their involvement in transactional sexual activity before age 18. Two New Zealand studies included an explicit focus on transgender youth and their involvement in and experiences of transactional sexual activity. In comparison to cis-gender youth, they have disproportionately high levels of involvement in survival sex, with seven of 47 respondents in Saphira and Herbert's (2004c) study identifying as transgender. Maori are also over-represented in survival sex statistics, with the same study showing that $40 \%$ of respondents identified as Maori (Saphira \& Herbert, 2004c).

\section{Conceptualising child prostitution: Victim or criminal}

Earlier works appear more likely to conceptualise young females using sex for survival as immoral, criminal or delinquent; however, these concepts persist despite an increasing body of knowledge confirming that children do not have the social, emotional, developmental or legal ability to consent to sexual acts (Lukman, et al., 2011). Dorais and Corriveau (2009) categorise girls involved in transactional sex as being sex slaves, submissives, independents or daredevils, thereby recognising the implicit coercive elements of their involvement, but suggesting girls whose behaviour falls in the latter categories have some degree of power over their circumstances. The perpetuation of the insecurities and inequities within society that often precipitate the need for sex for survival are largely ignored, while the individual is often pathologised and regarded as problematic (Peace, 2009). This construction is frequently seen in the media's portrayal of sex for survival, with the use of the word 'prostitute' conveying a sense of equal transactional power and the use of the word 'client' lending legitimacy 
to the illegal act (Goddard, 2005). The only distinction between child sexual abuse and the purchasing of sex from young people is payment to the victims, which does not equate to a moral transaction (Herman, 1987).

Despite laws stating that children under 16 cannot give informed consent (Dorais and Corriveau, 2009), the victims of this pervasive type of sexual exploitation are blamed for men's use of their bodies. The provision of helping services is often determined by helpers' perceptions of the victims as deserving or undeserving, with girls more likely to be considered worth helping if they conform to a gendered moral framework by demonstrating traditional 'female' values of passivity and chastity (Peace, 2009). For those deemed undeserving, a punitive approach is used to halt the 'delinquent' behaviour. This response indicates that the dominant perspective of the seventies and eighties of child prostitutes as over-sexualised temptresses still prevails in some settings (Peace, 2009), and demonstrates the continued unwillingness to differentiate between women's and children's involvement in transactional sex (Lukman, et al., 2011). Consequently, social and political constructs of morality in relation to sex for survival need to be considered when examining the context in which sex for survival occurs (Lukman, et al., 2011).

\section{Gender, power and society}

Societal beliefs and practices play a role in the continuation of survival sex. Patriarchal ideals contribute to a culture of silence and inaction surrounding survival sex, in part through the widely adhered-to myth that men cannot control their sexual wants and it is up to women and girls to set moral standards (Saphira \& Oliver, 2002). Furthermore, the internalisation of adults' messages about gender roles and sexuality contributes to children's propensity to become either a victim or a perpetrator of abuse (Peace, 2009). For example, girls are inducted into play depicting them as carers from a young age, while boys are generally encouraged to be aggressive, use actions and demonstrate power through play (Ennew, 1986). Further, girls are sexualised early in their appearances, a phenomenon increasingly targeted by women's and parents' groups (Odone, 2010). Desirability and attractiveness are promoted as ideals to which girls should aspire, leaving them vulnerable to manipulation from men who recognise and exploit this (Dorais \& Corriveau, 2009). Constructions of desirability also play a part in the demand aspect of sex for survival, with the media being saturated with ideals about young, newly developed teenagers as the ultimate sex object (Dorais \& Corriveau, 2009). Finally, as part of a patriarchal system, male violence towards women in a variety of contexts is regarded as normal and perpetuated through family cycles, leading to an entrenched gendered power imbalance (Shannon, et al., 2008).

\section{Pathways into survival sex}

\section{Coercion from gangs or individuals}

For girls, the pathway into survival sex is often through an intermediary such as a gang member or 'pimp'. In a gang or pimp context, the process of 'love-bombing' girls, that is, repeated declarations of love, protectiveness and affection often accompanied by presents, is usually followed by systematic degradation until the girls no longer distinguish between forced and consensual sex (Dorais \& Corriveau, 2009). The transition to total powerlessness at the hands of the gang members or pimps is characterised by dehumanising and violent acts, in conjunction with emotional manipulation and threats to withdraw affection (Dorais 
\& Corriveau, 2009). Following their work with an increasingly alarming number of clients affected by survival sex, Barnardos created a 'grooming model' to explain the process by which girls were drawn into transactional sex (Pearce, 2009). This model suggests that after beginning with the provision of love, gifts and excitement, perpetrators then facilitate emotional and physical dependence and ultimately coerce victims to generate income through transactional sex (Pearce, 2009). This is similar to Chase and Statham's (2005) theory, which identified the four stages of assuming control over victims as ensnaring through affection, isolating from family, assuming power over the girl's life and total dominance. Gang members and pimps often recruit from runaway spots and youth residences, and gain power over the victims by a 'trauma bond', through which fear, violence and gratitude act to ensure victims' submission (Jordan, Patel, \& Rapp, 2013). This has been likened to Stockholm Syndrome, as techniques such as violence, affection and degradation are used to facilitate dependence (Jordan, Patel, \& Rapp, 2013).

\section{Child sexual abuse}

Child sexual abuse has been long recognised as a precipitating factor in girls' decisions to use sex for survival. As sexual abuse can result in changes to thought processes, relational styles, mental health state and stress responses, it is a significant risk factor for sexual exploitation (Holger-Ambrose, et al., 2013; Ahrens, et al., 2012; Saphira \& Herbert, 2004a). In addition, sexual abuse creates a distorted perception of sexuality, sexual behaviour and self-worth (Ahrens, et al., 2012), and may be viewed as fulfilling a self-harming compulsion resulting from past abuse (Saphira \& Oliver, 2002). Consequently, transactional sex can be seen as a continuation of prior victimisation (Jordan, Patel, \& Rapp, 2013). Involvement in survival sex may then reinforce feelings of stigmatisation and marginalisation that began at the time of the initial victimisation (Ahrens et al, 2012). Studies drawn from a diverse range of countries and methodologies have demonstrated that between 40 and 60 percent of respondents engaging in transactional sex report historical sexual abuse, with the actual prevalence likely to be higher due to underreporting (Svensson, et al., 2012; Cobbina \& Oselin, 2011; Saphira and Herbert, 2004a; Silbert, 1981).

\section{Runaways, throwaways and marginalisation}

The reasons girls enter transactional sex other than sexual abuse or gangs are multifaceted, but there are common themes in the literature. Girls consistently report a lack of choice and the need to survive as driving them towards survival sex (Peace, 2009). Jordan, Patel, and Rapp (2013) use the terms runaway and throwaway to denote the circumstances in which children have left home and subsequently become victims. This reflects Ennew's (1986) explanation that children and young people without protective systems around them are easy targets for sexual exploitation. Also recognised as precipitants to sex for survival are physical and psychological abuse (Jordan, Patel, \& Rapp, 2013); children who have been in state or foster care (Ahrens, et al., 2012); homelessness, poverty and family breakdown (Ministry of Justice, 2001); alcohol and drug use (Ministry of Justice, 2002); and peer pressure (Cobbina \& Oselin, 2011). Where more than one risk factor is present, the effects may be compounded and result in demoralisation and the disintegration of self-efficacy, leading to sex for survival being seen as the only viable or easiest option (Caplan, 1984). People who identify as Maori or transgender are at increased risk, as both tend to exhibit increased clusters of risk factors which may work synergistically to create vulnerability to exploitation (Ministry of Justice, 2002). Transgender sex workers in Auckland have reported the development of their sexual identity as a reason for using survival sex, in conjunction with the 
perceived difficulty to obtaining alternative employment due to prejudicial attitudes held by potential employers (Worth, 2000; Boles \& Elifson, 1994). This signals two discrete arenas of youth development where discriminatory attitudes hinder natural transitory processes for gender-liminal young people.

\section{Financial desperation}

In the limited available research featuring New Zealand children and young people involved in transactional sex, poverty and economic pressures are consistently named as precipitants to entering sex work. This is consistent with studies conducted in Australia, where the need for accommodation, money, food and drugs were named as key reasons for transactional sexual activity (Grant, Grabosky, \& David, 1999). An unresponsive welfare system arguably plays a part in this drive to meet financial needs through survival sex, as the scarcity of financial support for young people living transient or chaotic lives perpetuates their reliance on survival sex (Abel \& Fitzgerald, 2008). A study featuring 17 adolescents using sex for survival showed that none were living with or receiving financial assistance from their families; a notable departure from 'typical' living situations of that age group (Abel \& Fitzgerald, 2008). Young people aged 16-17 can access an unemployment benefit only if they have children, and an independent youth benefit only if their caregivers confirm that qualifiable barriers to them living at home exist, which assumes a level of collaboration between child, parent and State that is often conspicuously absent (Abel \& Fitzgerald, 2008). In addition, the problem-solving skills needed to navigate formal systems and transcend bureaucratic barriers are undeveloped in adolescents, indicating a need for alternative processes for children and youth whose circumstances do not conform to the normative ideals inherent in these welfare policies (Gillies, 2005).

\section{Consequences of survival sex}

A host of physical, psychological and behavioural outcomes have been linked with survival sex. Desensitisation to violence is common, and approximately $47 \%$ of victims will sustain serious injuries while engaging in sex for survival (Silbert, 1981). This is often accompanied by a sense of powerlessness to escape (Silbert, 1981). Herman (1987) lists some of the common effects of transactional sex as difficulty building trusting or meaningful relationships, low mood, poor concentration, self-harming behaviours including drug and alcohol use, and possible poor sexual health outcomes such as diseases and pregnancy. Both Post-Traumatic Stress Disorder and Stockholm Syndrome are among the possible consequences, and the extent to which these are experienced are dependent on the victim's experiences of survival sex and his/her pathway out of it (Dorais \& Corriveau, 2009). Emotionally, victims are likely to feel invisible and worthless, and these feelings may persist throughout their lifetimes (Saphira \& Herbert, 2004b). Victims are also at risk of significantly poorer mental health outcomes (Svensson, et al., 2012; Ahrens, et al., 2012; Holger-Ambrose, et al., 2013).

\section{Ways forward}

Given that the issue of survival sex for children and young people has multiple causes and is associated with multiple manifestations of inequality and marginalisation, a multi-systemic approach to addressing it is required. It was previously suggested that social workers are in a position to make a significant difference to the experiences of youth who use sex for survival, as social workers' stated values and goals are consistent with addressing discrimination and 
contributing to social change (Herman, 1987). However, there is no recent literature outlining the social work role in combating survival sex. Victims of transactional sex commonly view professionals with distrust, indicating a further barrier to accessing services (Saphira \& Herbert, 2004b). Government has recognised that youth who engage in transactional sex need services that address their emotional, physical and spiritual needs, and help them to identify avenues of safety (Ministry of Justice, 2002). Street outreach programmes are considered the most effective with this client group, however their success is reliant on adequate funding, which in turn is dependent on sexual exploitation being prioritised as a social issue (Ministry of Justice, n.d). Street outreach initiatives could potentially be expanded to access victims through the internet, as many young people use this to engage with their perpetrators (Holger-Ambrose, et al., 2013). In addition, approaches to welfare provision that are inclusive and without substantive barriers may facilitate safer pathways for young people. Prevention initiatives may be successful if targeted at those known to be vulnerable to exploitation, such as children in foster care or with abuse histories (Jordan, Patel, \& Rapp, 2013). These initiatives should confront beliefs about prostitution; invite discussion about gender roles, power and relationships; and facilitate the building of trust between young people and social services (Dorais \& Corriveau, 2009).

\section{Conclusion}

Child and adolescent involvement in transactional sex for survival is an undeniable social problem, resulting in a range of adverse outcomes for children and young people. Society's widely held dominant ideals about gender, power and sexual desirability contribute to the perpetuation of transactional sex among young people. Common pathways through which victims begin using transactional sex include gangs and pimps, sexual abuse, and the absence of protective systems and subsequent lack of viable choices. While New Zealand's legal framework expressly prohibits the purchasing of sexual services from those under 18, insufficient policy and practice initiatives exist to provide an optimal level of support to such victims. Recommendations drawn from the literature include the extension of street outreach approaches to include internet-based strategies; changes to welfare provision for young people; the introduction of a cohesive nationwide service specifically for Maori; and the implementation of targeted prevention strategies to be delivered to young people vulnerable to sexual exploitation. In conclusion, the literature examined overwhelmingly supports the development of a social work role in supporting victims of transactional sex and in working with vulnerable young people to identify alternative pathways towards meaningful survival.

\section{References}

Abel, G. M., \& Fitzgerald, L. J. (2008). On a fast-track into adulthood: An exploration of transitions into adulthood for street-based sex workers in New Zealand. Journal of Youth Studies, 11(4), 361-376.

Ahrens, K. R., Katon, W., McCarty, C., Richardson, L. P., \& Courtney, M. E. (2012). Association between childhood sexual abuse and transactional sex in youth aging out of foster care. Child Abuse and Neglect, 36(1), 75-80.

Alvarez, M. B. (2012). Human trafficking is more than sex trafficking and prostitution: Implications for social work. Journal of Women and Social Work, 27(2), 142-152.

Ayre, P., \& Barrett, D. (2000). Young people and prostitution: An end to the beginning? Children and Society, 14, 48-59.

Boles J., \& Elifson K. (1994). The social organisation of transvestite prostitution and AIDS. Social Science and Medicine, $39,(1), 85$-93.

Caplan, G. M. (1984). The facts of life about teenage prostitution. Crime and Delinquency, 30(1), 69-74.

Chase, E, \& Statham, J. (2005). Commercial and sexual exploitation of children and young people in the UK: A review. Child Abuse Review, 14, 4-5. 
Cobbina, J. E., \& Oselin, S. S. (2011). It's not only for the money: An analysis of adolescent versus adult entry into street prostitution. Sociological Inquiry, 81(3), 310-232.

Crampton, D. (2013). Laws needed to clean up underage prostitution. Retrieved from http:/ / www.nzherald.co.nz/ nz/news / article.cfm?c_id=1\&objectid=10875195.

Dorais, M., \& Corriveau, P. (2009). Gangs and girls: Understanding juvenile prostitution. Montreal: McGill Queen's University Press.

Dorday, J. (2013). Girls pimped out by relatives - pastor. Retrieved from http:/ / www.nzherald.co.nz/nz/news/ article.cfm?c_id=1\&objectid=10874035.

Ennew, J. (1986). The sexual exploitation of children. Cambridge: Polity Press.

Gillies, A. (2013). MP finds 13-year-old prostitutes taking \$600 a night. Retrieved from http: / / www.nzherald.co.nz/ nz/news / article.cfm?c_id=1\&objectid=10875195.

Gillies, V. (2005). Meeting parents' needs? Discourses of 'support' and 'inclusion' in family policy. Critical Social Policy, 25(1), 70-90.

Goddard, C. (2005). The rapists' camouflage: 'Child prostitution.' Child Abuse Review, 14, 275-291.

Grant A., Grabosky P., \& David F. (1999). The commercial sexual exploitation of children. Australian Institute of Criminology paper presented at the Children and Crime: Victims and Offenders Conference at Brisbane.

Herman, K. J. (1987). Children sexually exploited for profit: A plea for a new social work priority. National Association of Social Workers, 523-527.

Holger-Ambrose, B., Langmade, C., Edinburgh, C., \& Saewyc, E. (2013). The illusions and juxtapositions of commercial sexual exploitation among youth: Identifying effective street-outreach strategies. Journal of Child Sexual Abuse, 22(3), 326-340.

Jordan, J., Patel, B., \& Rapp, L. (2013). Domestic minor sex trafficking: A social work perspective on misidentification, victims, buyers, traffickers, treatment, and reform of current practice. Journal of Health Behaviour in the Social Environment, 23(3), 356-367.

Lukman, Z. M., Fauziah, I., Rusyda, H. M., Sarnon, N., Mokhtar, M. K., Alavi, K., Chong, S. T., Nen, S., \& Fatimah, D. (2011). Betrayal of trust: The involvement of children in prostitution. Journal of Social Sciences and Humanities, 19(5), 49-56.

Ministry of Justice. (2001). Protecting our innocence: New Zealand's national plan of action against the commercial sexual exploitation of children. ISBN 0-478-20167-2.

Ministry of Justice. (2002). Child prostitution. Retrieved from http: / / www.justice.govt.nz / policy / commercial-property-and-regulatory / prostitution/ prostitution-law-review-committee / publications / plrc-report/7-the-use-ofuder-age-people-in-prostitution.

New Zealand Parliament. (2004). Questions for oral answer: Children - prostitution. Retrieved from http: / www. parliament.nz/en-NZ/PB/Business/QOA/6/2/1/.

Odone, C. (2010). Well done, Mumsnet, for campaigning against gross 'sexy' products for little girls. Retrieved from http: / / blogs.telegraph.co.uk/news / cristinaodone/100034558/well-done-mumsnet-for-campaigning-againstgross-sexy-products-for-little-girls/.

Peace, J. (2009). Young people and sexual exploitation: 'It's not hidden, you just aren't looking'. New York: Routledge-Cavendish.

Plumridge L. \& Abel G. (2001) A'segmented' sexual industry in New Zealand: Sexual and personal safety of female sex workers. Australian and New Zealand Journal of Public Health, 25(1), 78-83.

Saphira, M. (2001). The commercial exploitation of children. Auckland: ECPAT NZ.

Saphira, M., \& Herbert, A. (2004a). Victimisation among those involved in underage commercial sexual activity. Retrieved from http: / / www.ecpat.org.nz/pdf/victimisation.pdf.

Saphira, M., \& Herbert, A. (2004b). Exiting commercial sexual activity. Auckland, New Zealand: ECPAT NZ.

Saphira, M., \& Herbert, A. (2004c). The involvement of children in commercial sexual activity. Auckland, New Zealand: ECPAT NZ.

Saphira, M., \& Oliver, P. (2002). A review of literature on child prostitution. Social Policy Journal of New Zealand, 19, 141-163.

Shannon, K., Kerr, T., Allinott, S., Chettiar, J., Shoveller, J., \& Tyndall, M. W. (2008). Social and structural violence and power relations in mitigating HIV risk of drug-using women in survival sex work. Social Science and Medicine, 66, 911-921.

Shepherd, S. (2010). Police target child prostitutes in Auckland City. Retrieved from http: / / www.3news.co.nz/ Policetarget-child-prostitutes-in-Auckland-City/tabid/423/articleID/160528/Default.aspx.

Silbert, M. H. (1981). Sexual child abuse as an antecedent to prostitution. Child Abuse and Neglect, 5, $407-411$.

Svensson, F., Fredlund, C., Goransvedin, C., Priebe, G., \& Wadsby, M. (2012). Adolescents selling sex: Exposures to abuse, mental health, self-harm behaviour, and the need for help and support - a study of a Swedish national sample. Informa Healthcare, 581-585.

Worth H. (2000). Up on K Road on Saturday night: sex, gender and sex work in Auckland. Venereology, 13(1) 15-24. 